\title{
EVALUATION OF SINGLE PHASE TRANSFORMERLESS PHOTOVOLTAIC INVERTERS
}

\author{
Ahmad Syed $^{1}$ and S.Tara Kalyani ${ }^{2}$ \\ Dept. of Electrical and Electronics Engineering \\ Jawaharlal Nehru Technological University \\ Hyderabad, India
}

\begin{abstract}
Transormerless inverters are attractive solution for the grid connected photovoltaic (PV) systems. Unfortunately, it has issues on galvanic isolation between PV systems to the grid. When the galvanic isolation disappears from the PV inverter, leakage currents will flow in a resonant circuit formed by the ground capacitance, the converter, the ac filter and the grid. In order to avoid the leakage currents, various transformerless inverters have been proposed using different topologies to generate constant common mode voltage. In this paper, various recently-proposed transformerless PV inverters are investigated. Their performances are compared and analyzed.
\end{abstract}

\section{Keywords}

Grid connected photovoltaic systems, transformerless inverter, parasitic capacitance, common mode voltage, leakage current.

\section{Introduction}

Renewable energy sources are key issues in the attempt to address energy problems. Among the all energy sources, solar energy is one of the most up to date techniques. However, the applications are limited by relatively high cost in comparison with traditional sources. Today's world needs more energy due to skyrocketing population and industries. Hence, renewable energy plays an important role to ensure a better future. Solar energy has greatest role in present trend because it is free from pollution and green. PV(Photovoltaic) systems with grid connected are typically categorized into two types i.e. with transformer and without transformer. For the low power applications, a single phase converter is usually used, embedded with low- or highfrequency transformer. Nevertheless, the transformer requires few numbers of power stages and thus, the design of highly-efficient, low-cost and small-size inverters become a difficult task [1].

On the other hand, it is possible to remove the transformer from the inverter in order to reduce losses, size and cost of those systems, namely transformerless PV systems. However, the resulting galvanic connection between the grid and PV array introduces ground leakage current path due to the effect of solar panel parasitic capacitance [2] e.g. 10-100nF/kwp. As a result, higher leakage currents give rise to EMC problems and increase the harmonics injected into the grid. Certain standards such as the DIN VDE 0126-1-1[3], impose the disconnection of the PV array from the converter if the ground leakage current exceeds its prefixed limits. Moreover the harmonic content and its amplitude depend upon the converter topology and parameters of the resonant circuit.

Recently, many solutions have been proposed based on the converter topology and PWM methods [16]-[17]. Most of the efforts are to limit the leakage currents under $300 \mathrm{~mA}$ to meet the 
standard requirement. Based on the topology and controlling methods, the following observations are obtained [8-14]:

- Disconnect the PV array from the grid: dc bypass method (H5) and ac bypass (HBZVR, HERIC).

- Connect the negative terminal of PV panels with the neutral line of utility grid

- Clamping techniques (H6, HBZVR-D).

All the transformerless PV inverters are designed based on the condition when CMV is constant throughout the different switching states. In transformerless PV inverters [5]-[6], a main design criterion is to reduce the leakage current flowing through the parasitic capacitance to the ground. In this paper, a comparison based on simulation results of the different methods is evaluated.

\section{Common-mode voltage and leakage current analysis in transformerless PV Inverter.}

When transformer is removed from the grid connected inverter, galvanic is created in a resonant circuit through parasitic capacitance, filters inductance, grid and includes leakage current flowing to the ground as shown in Figure 1.

In order to analyze the system CMV, differential mode voltage behavior, the following steps have to be considered:

In case of single-phase system, the common mode and differential mode behavior are derived between two phases with respective to the neutral as shown in Figure1. (a)-(c) [4].

In any transformerless PV inverter CMV is defined as the average of the sum of voltages between the outputs and common reference i.e. phase A, B and common reference $\mathrm{N}$

$\mathrm{V}_{\mathrm{cm}-\mathrm{AB}}=\frac{\mathrm{V}_{\mathrm{AN}}+\mathrm{V}_{\mathrm{BN}}}{2}$

The differential mode voltage is defined as the difference between the two voltages with common reference $\mathrm{N}$

$$
\mathrm{V}_{\mathrm{dm}}=\mathrm{V}_{\mathrm{AN}}-\mathrm{V}_{\mathrm{BN}=} \mathrm{V}_{\mathrm{AB}}
$$

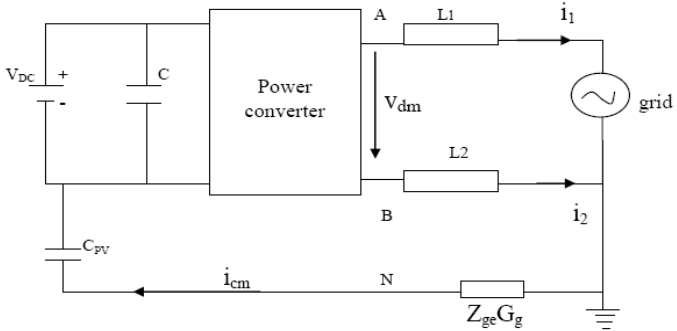

(a)

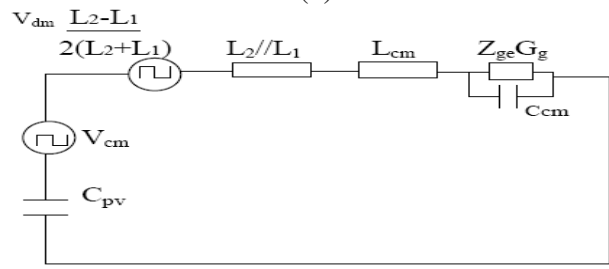


(b)

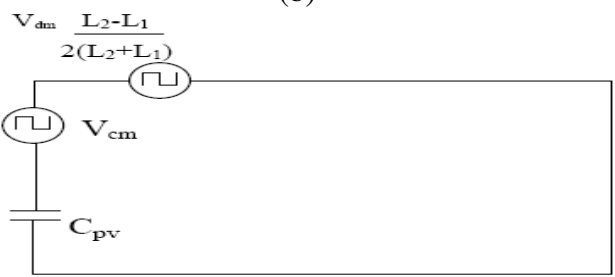

(c)

Figure 1. (a) System full model, (b) detailed common model, (c) simplified common mode model

The voltages between the converter output points and the reference point $\mathrm{N}$ can be expressed as:

$$
\begin{aligned}
& V_{\mathrm{AN}}=\mathrm{V}_{\mathrm{dm}-\mathrm{AB}}+\frac{\mathrm{V}_{\mathrm{cm}-\mathrm{AB}}}{2} \\
& \mathrm{~V}_{\mathrm{BN}}=-\mathrm{V}_{\mathrm{dm}-\mathrm{AB}}+\frac{\mathrm{V}_{\mathrm{cm}-\mathrm{AB}}}{2}
\end{aligned}
$$

Common mode current is defined as

$$
\mathrm{i}_{\mathrm{cm}}=\mathrm{i}_{1}+\mathrm{i}_{2}
$$

\section{Different transformerless PV inverters.}

\subsection{Full bridge inverter}

The full bridge (FB) inverter is shown in Figure. 2 [7]. The FB inverter can be modulated with either unipolar or bipolar modulation techniques.

In unipolar modulation, both leg A (S1, S2) and leg B (S3, S4) switched with high frequency with mirrored sinusoidal reference. And two zero output voltage states are possible: S1, S3=ON and $\mathrm{S} 2, \mathrm{~S} 4=\mathrm{ON}$. With this modulation technique, the implementation is more feasible and popular. However, high CMV appears and leads to high leakage currents. In the bipolar modulation, both legs $\mathrm{A}$ and $\mathrm{B}$ are switched simultaneously in the diagonal pairs, i.e., positive half cycle $\mathrm{S} 1=\mathrm{S} 3$ and negative half cycle $\mathrm{S} 2=\mathrm{S} 4$. The advantage of

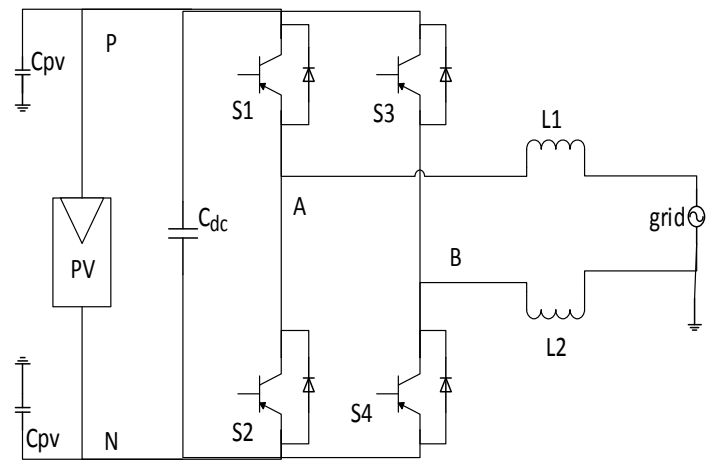

Figure 2.single phase FB inverter 


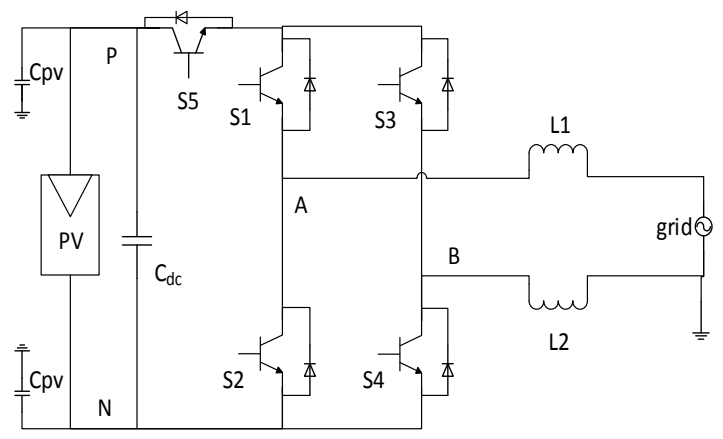

Figure 3.H5 topology.

Bipolar modulation technique is the constant CMV which eliminates the leakage currents. However, bipolar modulation technique causes large ripple currents which deteriorated the power quality and the efficiency.

Recent topologies are combining the constant CMV of the bipolar modulation with those of the unipolar modulation (the three level voltage output, absence of the ripple current and high efficiency).

\subsection{DC bypasses method:}

In dc bypass method, the inverter gets disconnected from the grid in the dc side. The galvanic isolation can be realized in freewheeling state with proper modulation. The basic FB inverter adds switches on the de side as de-decoupling switch such as H5 topology as shown in Figure. 3. H5 topology was developed by SMA technologies.

Zero voltage vectors can be realized when S5 OFF. The freewheeling path is created via switch S1 and the anti-parallel diode of switch S3 during the positive active state. Similarly, during negative active state, freewheeling path is created via switch S3 and the anti-parallel diode of switch S1.

Unfortunately, dc bypass method such as H5 topology is not able to maintain the CMV exactly at VDC/2 [8]. The leakage currents are still flowing with respect to the parasitic parameters of the resonant circuit. Beside floating CMV, another disadvantage is higher conduction loss due to more switches in the conduction path.

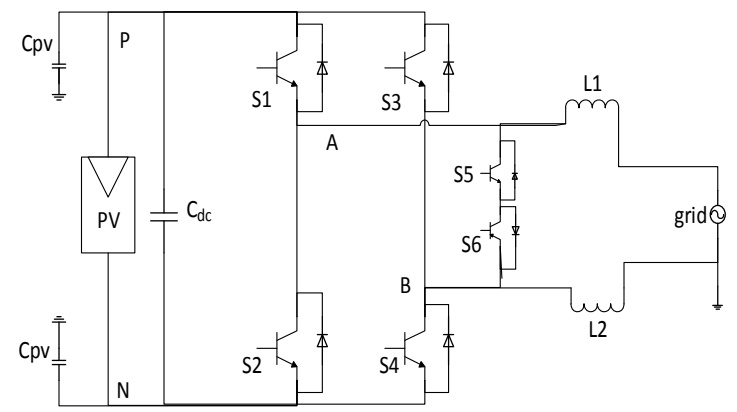

Figure 4. HERIC topology 


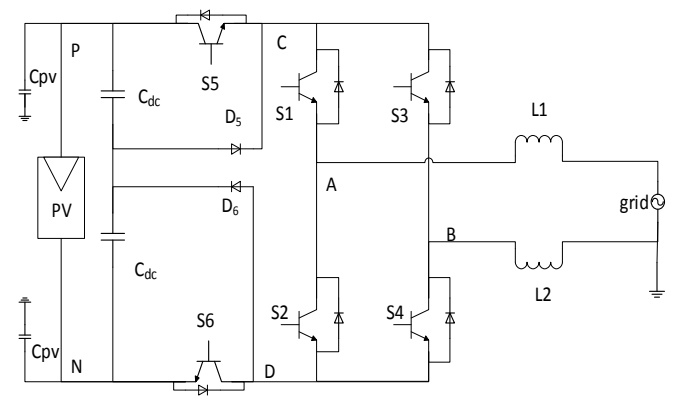

Figure 5.H6 topology

\subsection{AC bypass method:}

In ac bypass method, switches or diodes are added on the ac side of the inverter to create the freewheeling path. HERIC (High efficient and reliable inverter concept) [9] topology is implementing this method as shown in Figure.4. HERIC topology combines the advantages of the both unipolar and bipolar modulation techniques.

In ac-decoupling method, the significant difference from dc-decoupling method is the utilization of less switches in conduction mode (only 2 switches). This helps to reduce the losses as compared to dc-decoupling method. During the freewheeling states, it is necessary to generate the CMV at exactly VDC/2 to eliminate the leakage current. Similar to dc bypass method, ac bypass method fails to generate the constant CMV.

\subsection{Clamping method}

This method improves the common mode behavior of the decoupling method, with one clamping branch connected to the midpoint of the dc link to realize constant CMV. Figure.5 shows one of the topology employing clamping method; FB-DCBP (full bridge dc bypass diode clamp) [10].

Positive active vector can be realized via switches pair S1, S4. During this period, S5 and S6 commutate at the switching frequency. The negative active vector can be realized via S2 and S3. S5, S6 commutate at the switching frequency. Zero voltage vectors are realized when switch S5 and S6 are OFF. In this realization the voltage across the VAB, VCD tends to zero. In order to overcome these issues, two additional diodes such as D5 and D6 are used to fix freewheeling path voltages exactly half of the dc input voltage i.e. $\mathrm{VAN}=\mathrm{VBN}=\mathrm{VDC} / 2$.

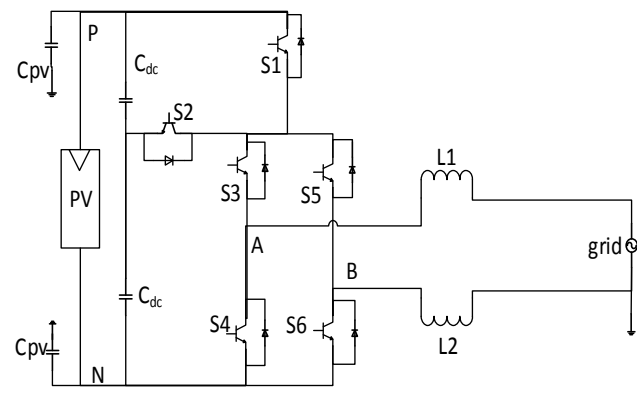

Figure 6.oH5 topology 


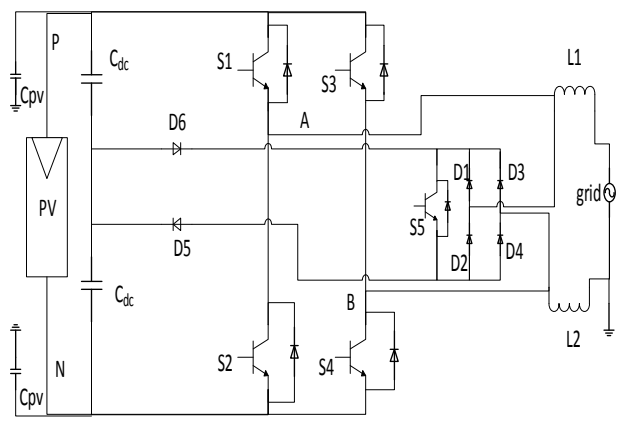

Figure 7.HBZVR-D topology

Furthermore, the CMV is clamped at constant with the help of clamping diodes in CMV clamping method. In other words, the leakage currents are reduced significantly, approximately zero. FBDCBP topology generates unipolar (three level) output voltage. Therefore, it has very high efficiency and becomes an attractive solution for the transformerless PV inverter.

Another recently proposed topology which employs clamping method is HBZVR-D (H-bridge zero voltage state rectifier diode) [14] as shown in Figure.7. The operating principle is similar to above discussed topology, except in freewheeling periods, with the help of protection circuit formed by one active switch and diode. In this topology the main drawback is the bipolar output voltage due to the dead time period between the conduction and freewheeling mode. This effect can be minimized with proper setting of the dead time period. It is high in efficiency and low leakage current compare to FBDCBP because of ac-decoupling family.

And another clamping topology such as oH5 proposed in [11] as shown in Figure.6. It is similar to above clamping methods instead of clamping branch components such as clamping takes place using switches such as S1, S2. However, it has high conduction losses due to more switches utilized in conduction path as compared to HBZVR-D topology. The other drawback of oH5 topology is voltage balancing on the capacitors due to dispersion of the component and parasitic parameters. This effect can be minimized by using one simple resistor across the switch or capacitor. In conclusion clamping method topologies such as FBDCBP, HBZVR-D \& oH5 has very attractive solutions for the transformerless PV inverters compare to the dc, ac decoupling methods due to improved common mode voltages and approximately zero leakage current. Moreover, HBZVR-D has high efficiency among the other clamping topologies.

\section{Simulation and Discussions}

The simulation of different transformerless PV inverters was performed using the MATLAB SOFTWARE with parameters based on Table 1. In this section, comparison of different parameters such as output voltage, common mode voltage (CMV), leakage current and current total harmonic distortion (THD) of the various transformerlss inverter are discussed. [15] 
'Electrical and Electronics Engineering: An International Journal (ELELIJ) Vol 4, No 2, May 2015

Table1: Selected parameters in simulation

\begin{tabular}{|c|c|}
\hline Filter inductance L1, L2 & $1.8 \mathrm{mH}$ \\
\hline Filter capacitance $\mathrm{C}_{\mathrm{f}}$ & $2 \mu \mathrm{F}$ \\
\hline Load resistance & $15 \Omega$ \\
\hline Input dc voltage VDC & $400 \mathrm{~V}$ \\
\hline $\begin{array}{c}\text { Dc-link capacitor } \mathrm{C}_{\mathrm{dc}} \\
\text { Parasitic capacitance of the } \\
\text { PV array Cpv }\end{array}$ & $250 \mu \mathrm{F}$ \\
\hline $\begin{array}{c}\text { Switching frequency } \mathrm{F}_{\mathrm{sw}} \\
\text { a }\end{array}$ & $100 \mathrm{nF}$ \\
\hline
\end{tabular}

The full bridge with unipolar modulation has three level output voltage as well as good efficiency. However, this topology generates varying common mode voltages; it causes high leakage currents as shown in Figure.8 (a). This topology is not suitable for the transformerless PV inverter due to safety issue from high leakage current.

In case of bipolar modulation, it has two level output voltage. The full bridge inverter with bipolar modulation does not generate the varying CMV thus significantly reduce the leakage current as per standards as shown in Figure.8 (b). This topology helps to avoid the injection of dc current into the grid [10]. However, full bridge bipolar modulation generates high current $\%$ THD $(3.84 \%)$ such as current ripples and switching losses. 
`Electrical and Electronics Engineering: An International Journal (ELELIJ) Vol 4, No 2, May 2015
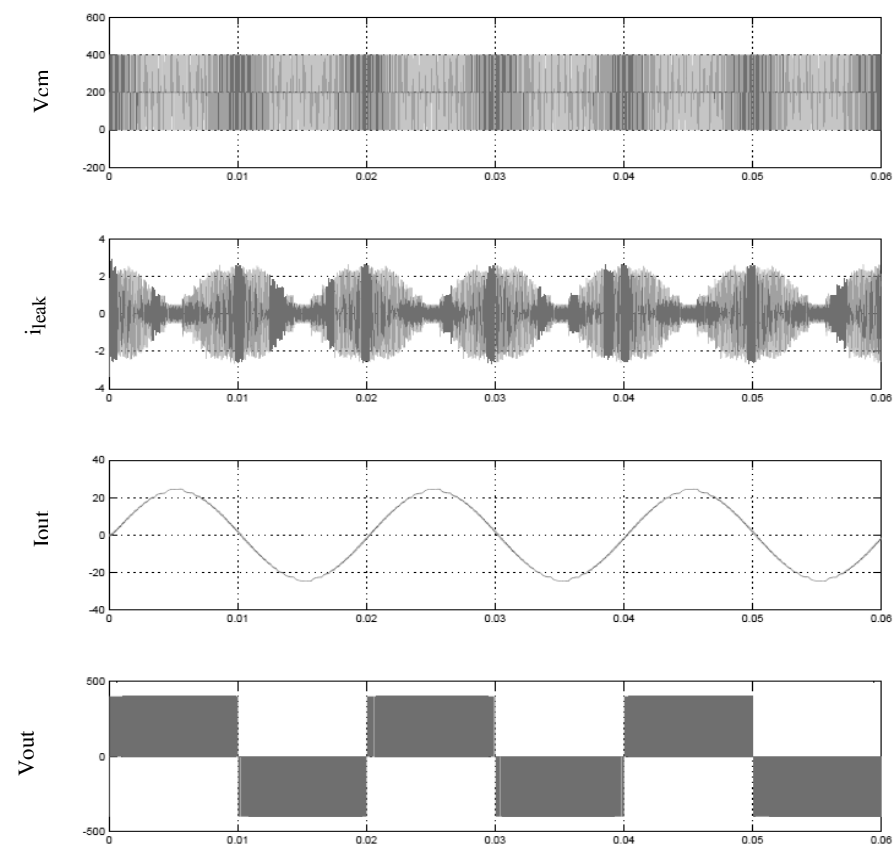

Time in Sec

(a)
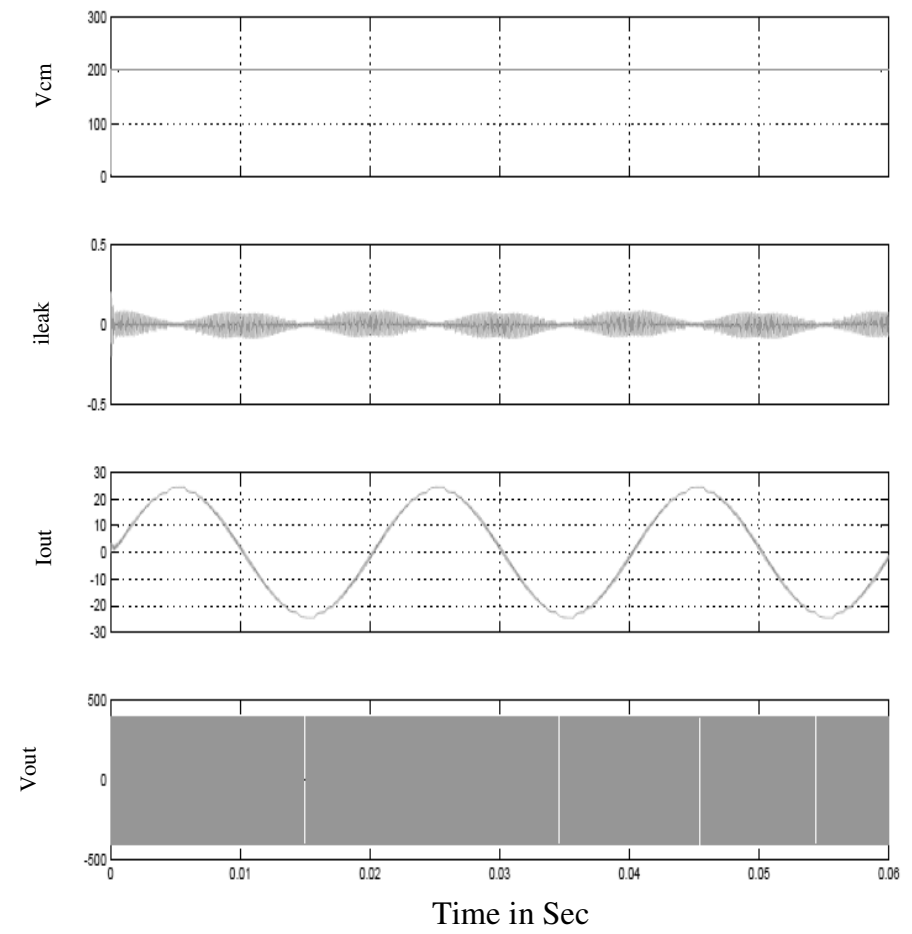

(b) 
'Electrical and Electronics Engineering: An International Journal (ELELIJ) Vol 4, No 2, May 2015

Figure.8 (a), (b). Common mode voltage (CMV), leakage current ( $\left.\mathrm{i}_{\text {leak }}\right)$, output current (Iout) and output voltage (Vout) for full bridge unipolar and bipolar PWM
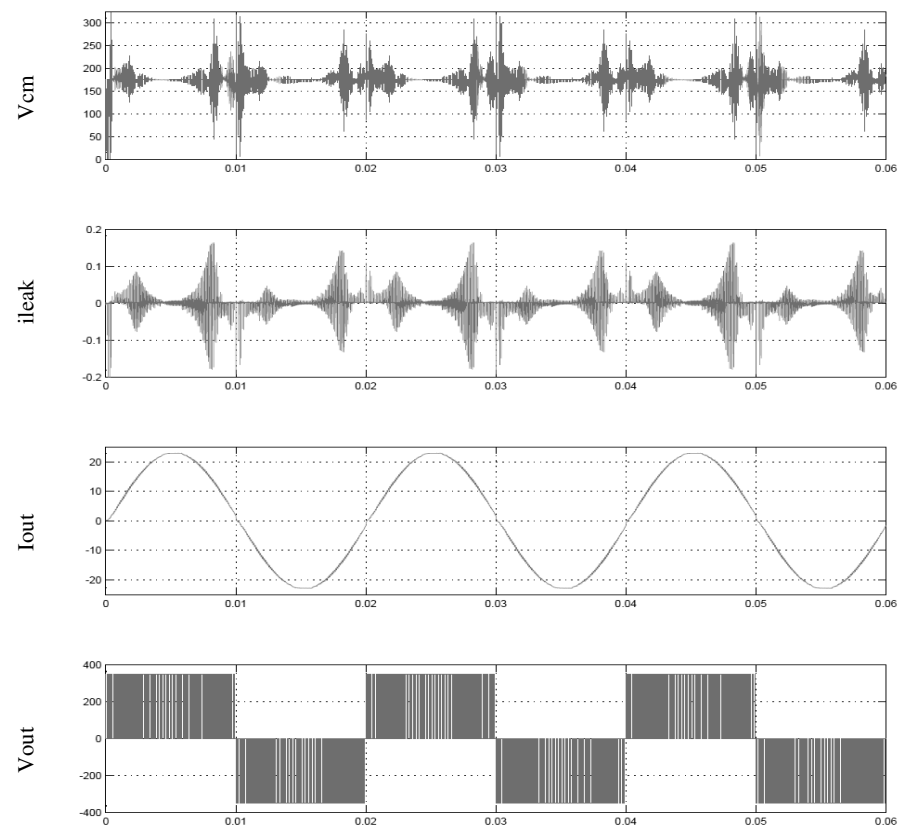

Time in Sec

(a)
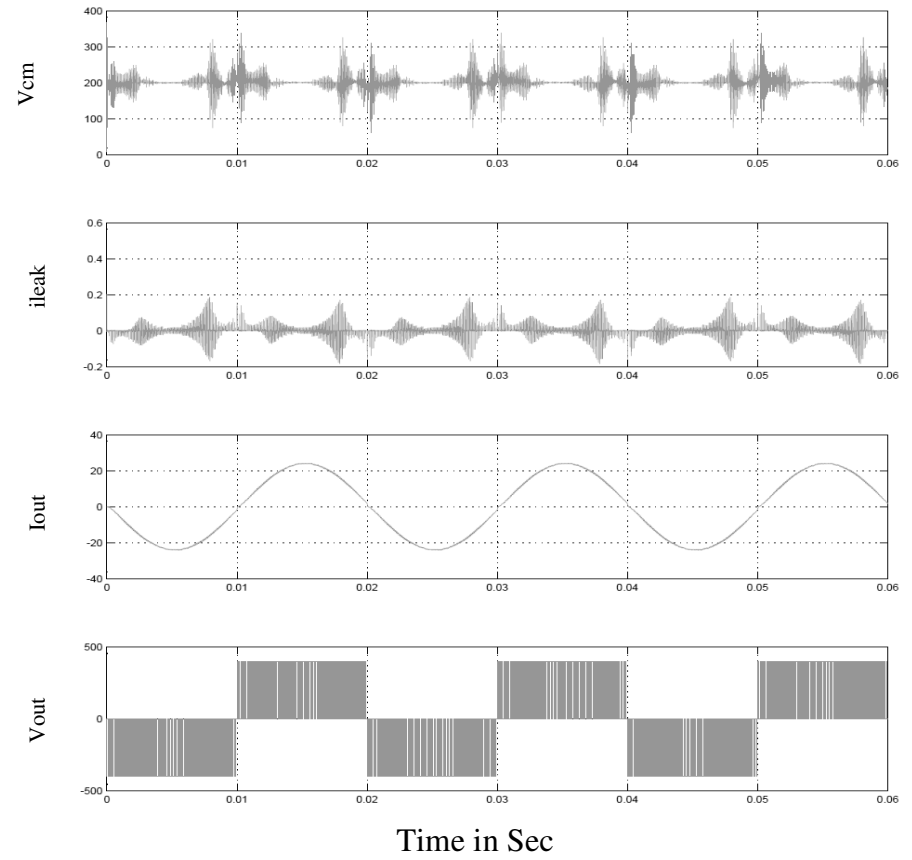

(b) 
`Electrical and Electronics Engineering: An International Journal (ELELIJ) Vol 4, No 2, May 2015
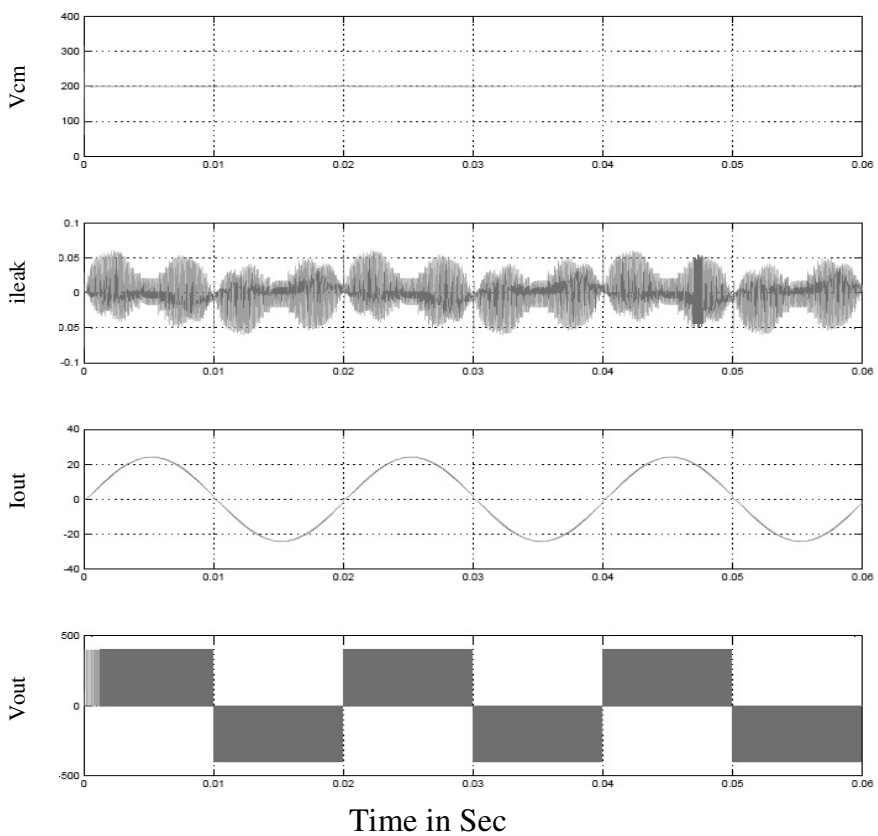

(c)
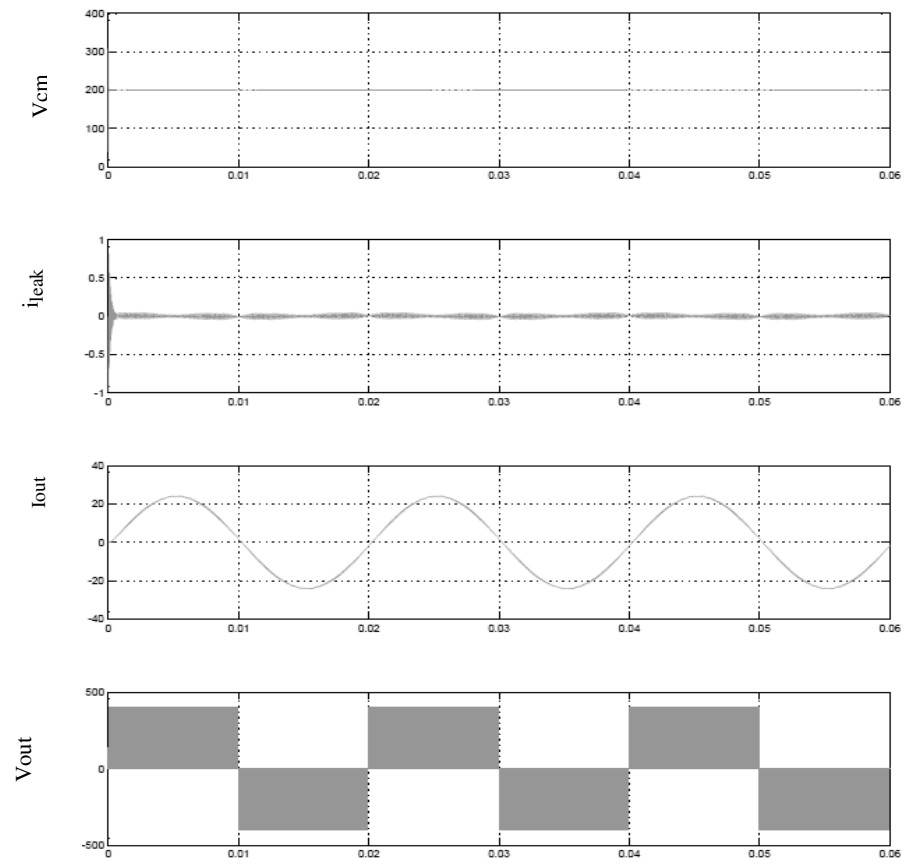

Time in sec

(d) 
`Electrical and Electronics Engineering: An International Journal (ELELIJ) Vol 4, No 2, May 2015
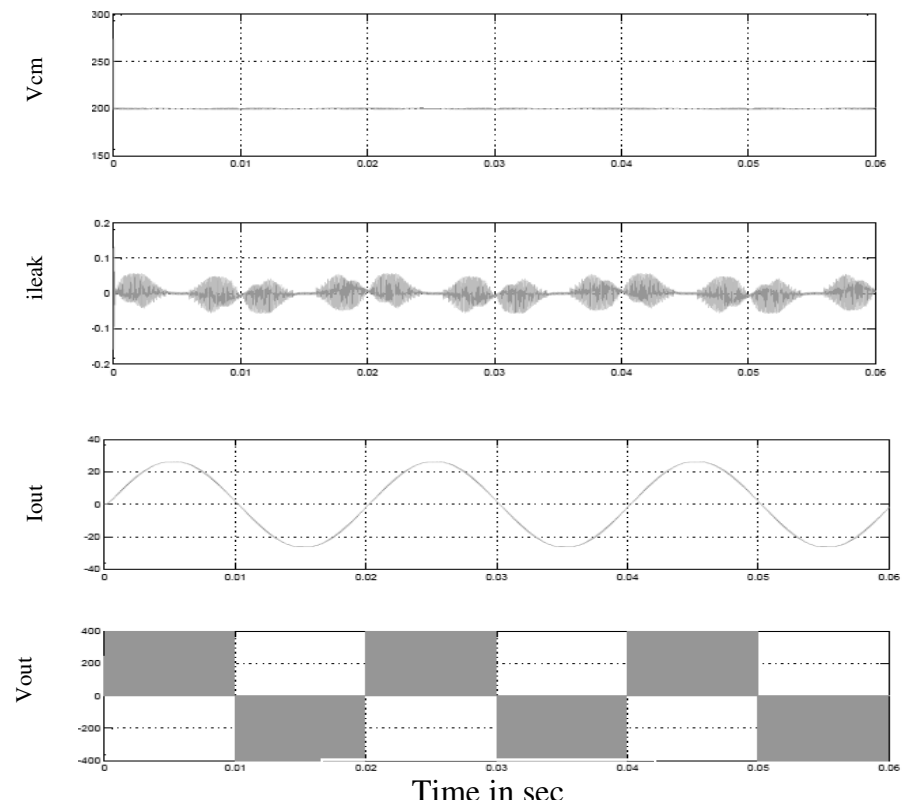

(e)

Figure 9.The performance analysis for (a) H5, (b) HERIC,(c) FBDCBP, (d) oH5, (e) HBZVR-D.

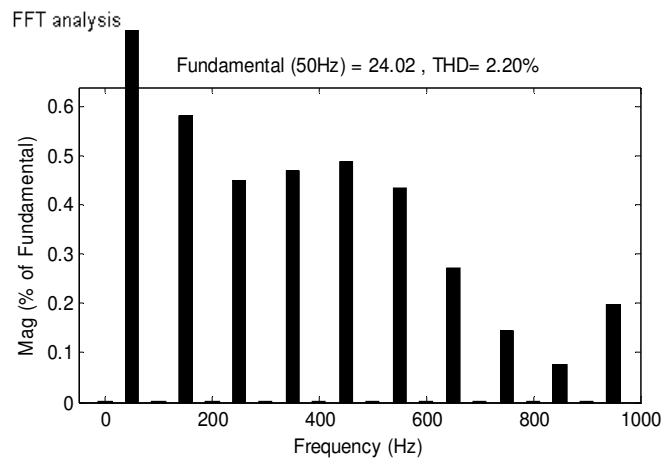

(a)

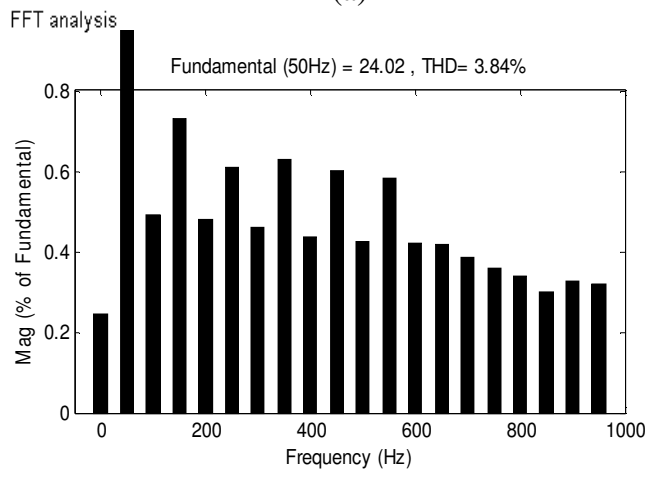

(b) 
`Electrical and Electronics Engineering: An International Journal (ELELIJ) Vol 4, No 2, May 2015

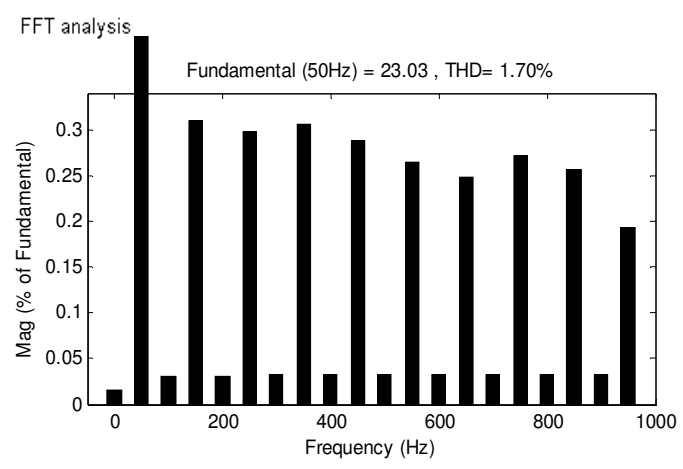

(c)

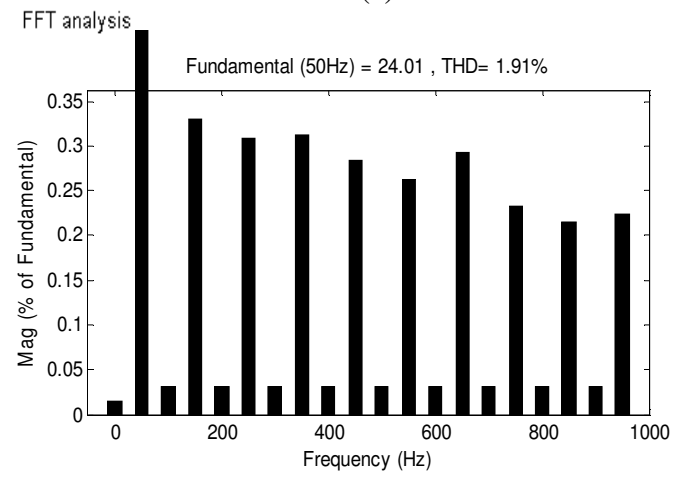

(d)

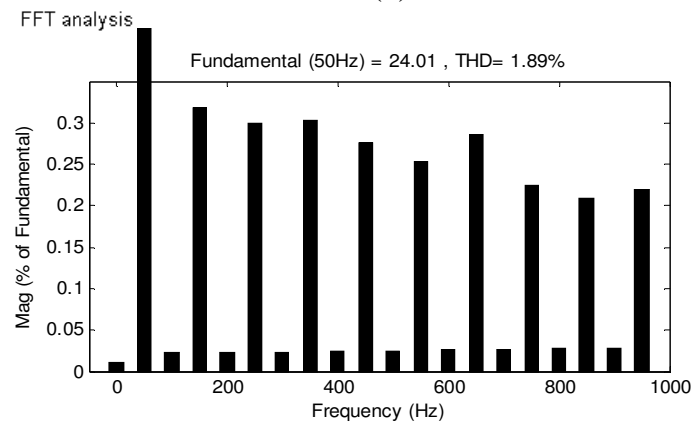

(e)

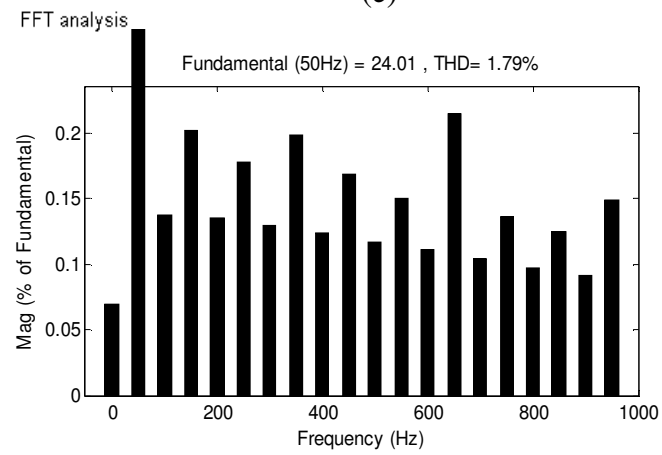

(f) 


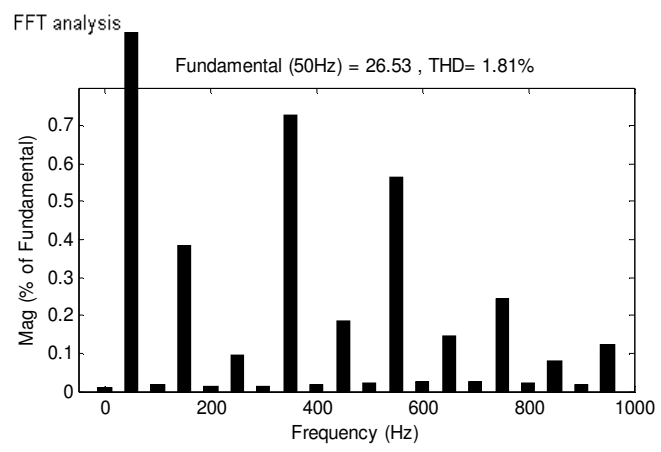

(g)

Figure 10.The Harmonic analysis for (a)FB-Unipolar,(b)FB-Bipolar, (c)H5,(d)HERIC,(e)FBDCBP,(f)oH5,(g)HBZVR-

The performance analysis of CMV clamping family (FBDCBP, HBZVR-D, oH5) and the dc bypass family (H5), ac bypass family (HERIC) are shown in Figures 9(a)-(e). Dc- and ac-bypass families fail to generate constant CMV as shown in Figure. 9 (a) and Figure.9 (b) respectively. This injects the ripple to the grid current which increases the \% current THD as shown in Figure.10 (a)-(b). On the other hand, FBDCBP, HBZVR-D and oH5 topologies improve the common-mode behavior by introducing the CMV clamping branch. The CMV is constant which eliminate the leakage current as shown in Figure.9(c)-(e). The current THD is almost similar which is much better than the bipolar modulation technique due to very low leakage current.

Among the recently proposed topologies, CMV clamping techniques are very attractive solution for the transformer less PV inverters due to high efficiency and very low leakage current. Table.2 summarizes the evaluations of different methods including advantages and disadvantages with selected topologies.

\section{CONCLUSION}

A line transformer is omitted in a PV system, galvanic isolation problems occur between the PV to the grid. Besides this issue high leakage current flowing through the parasitic elements of the resonant circuit, for the safety issue it can be minimized as per standards VDE 0126-1-1.To overcome these issues various transformerless PV inverters are proposed with different operating principles, which has to minimize the critical issues on common mode voltage and leakage current. Such way that number of topologies can be designed by the basic full bridge inverter, which has to disconnect the switches from dc, ac side in freewheeling states such as H5, HERIC topologies belongs to this category and clamp the voltage to the constant level using different clamping branches, which belong to this category such as FBDCBP, HBZVR-D and oH5.In simulation results the full bridge inverter with unipolar and bipolar PWM are not suitable to the transformerless PV inverters due to high leakage current and losses. And compare to the dc bypass method ac bypass methods have high efficient, besides this, still leakage current flowing in both topologies due to fluctuating potentials occurs at PV array. In clamping topologies such as FBDCBP, HBZVR-D and oH5 are minimizing the leakage current approximately zero with improved constant common mode voltages.

Furthermore in simulation results show that oH5, HBZVR-D is very attractive solutions for the transformerless systems. Besides this, harmonic issues are analyzed using fast Fourier transform (FFT) analysis \% THD is very low in H5 among the other topologies such as FB-unipolar, bipolar, HERIC, FBDCBP, HBZVR-D and oH5.However, HERIC manage to achieve the maximum efficiency but poor performance in terms of the common mode behavior. But unfortunately H5 
also fails in constant common mode behavior moreover it has low efficiency with high leakage current flowing in a circuit. On the other hand HERIC supplies the active power to the grid when in ideal case and also this process can lead to extra losses because some power would not be fed to the grid. To overcome these all shortcomings further investigations will be done.

Hence, this paper analyzes and compares the performance of the various evaluation methods of single phase transformerless PV inverters for the selected topologies do not eliminate the leakage current completely. It includes working principles and their control strategies were explained as well. And all topologies are validated by simulation and now they are being assemble to verify the experimental results.

Table. 2

\begin{tabular}{|c|c|c|}
\hline $\begin{array}{l}\text { Evaluation } \\
\text { methods with } \\
\text { Topologies }\end{array}$ & Advantages & Disadvantages \\
\hline FB- unipolar & $\begin{array}{c}\text { Three level output voltage, } \\
\text { High efficiency }\end{array}$ & High leakage current \\
\hline FB-bipolar & $\begin{array}{c}\text { Constant CMV } \\
\text { Low leakage current }\end{array}$ & large current ripples \\
\hline $\begin{array}{c}\mathrm{H} 5 \\
\text { (DC } \\
\text { BYPASS) }\end{array}$ & $\begin{array}{l}\text { Three level output voltage, } \\
\text { low current ripple }\end{array}$ & $\begin{array}{l}\text { Higher conduction } \\
\text { losses, variable CMV }\end{array}$ \\
\hline $\begin{array}{c}\text { HERIC } \\
(\text { AC } \\
\text { BYPASS })\end{array}$ & $\begin{array}{c}\text { Three level output voltage, } \\
\text { high efficiency }\end{array}$ & $\begin{array}{l}\text { Injection of reactive } \\
\text { power into the grid } \\
{[12], \text { Floating CMV }}\end{array}$ \\
\hline $\begin{array}{l}\text { FBDCBP (H6) } \\
\text { (CLAMPING } \\
\text { METHODS) }\end{array}$ & $\begin{array}{c}\text { Constant CMV, low leakage } \\
\text { current }\end{array}$ & $\begin{array}{c}\text { Higher conduction } \\
\text { losses, variable CMV }\end{array}$ \\
\hline HBZVR-D & $\begin{array}{c}\text { Constant CMV, Very low } \\
\text { leakage current, high } \\
\text { efficiency }\end{array}$ & $\begin{array}{l}\text { Bipolar output voltage } \\
\text { in dead time period }\end{array}$ \\
\hline oH5 & Very low leakage current & Voltage balancing \\
\hline
\end{tabular}

\section{REFERENCES}

[1] B. N. Alajmi, K. H. Ahmed, G. P. Adam, and B. W. Williams, "Single-Phase single-stage transformerless grid-connected PV system," IEEE Trans. Power Electron. vol. 28, no. 6, pp. 2664 2676, Jun. 2013.

[2] M. Calais and V. G. Agelidis, "Multilevel converters for single- phase Grid Connected photovoltaic systems-an overview,” in Proc. IEEE Int. Symp Ind. Electron. Jul. 1998, vol. 1, pp. 224-229

[3] Automatic Disconnection Device between a Generator and the Public Low-Voltage Grid, DIN Electro technical Standard DIN VDE 0126-1-1, 2005.

[4] E. Gubia, P. Sanchis, A. Urs'ua, J. Lopez, andL.Marroyo, "Ground Currents in single-phase transformerless photovoltaic systems,” Prog. Photovoltaic., Res. Appl., vol. 15, no. 7, pp. 629-650, Nov. 2007

[5] M. Calais, J.Myrzik, T. Spooner, and V. G. Agelidis, "Inverters for Single-phase grid connected photovoltaic system - an overview,” in Proc. IEEE Power Electron. Spec. Conf., 2002, pp. 19952000. 
`Electrical and Electronics Engineering: An International Journal (ELELIJ) Vol 4, No 2, May 2015

[6] J. M. A. Myrzik, and M. Calais, "String and module integrated inverters for single-phase grid connected photovoltaic system - a review," Power Technology Conference Proceedings, 2003 IEEE Bologna, vol. 2, June 2003

[7] N. Mohan, T. M. Undeland, and W. P. Robbins, Power Electronics: Converters, Applications and Design, 2nd ed., New York: John Wiley \&Sons, Inc., 1995.

[8] M. Victor, F. Greizer, S. Bremicker, and U. H"ubler, "Method of converting a direct current voltage from a source of direct current voltage,more specifically from a photovoltaic source of direct current voltage, into an Alternating current voltage," U.S. Patent 7411 802, Aug. 12,2008

[9] S. Heribert, S. Christoph, and K. Jurgen, "Inverter for transforming a DC voltage into an AC current or an AC voltage," Europe Patent 1369 985(A2), May 13, 2003.

[10] R.Gonzales,J. Lopez, P. Sanchis, and L. Marroyo, "Transformerless Inverter for single phasephotovoltaic systems," IEEE Transactions on Power Electronics, vol. 22, no. 2, pp. 693-697, March 2007.

[11] H. Xiao, S. Xie, Y. Chen, and R. Huang, “An optimized transformerless photovoltaic grid- connected inverter,” IEEE Trans. Ind. Electron., vol58,no. 5, pp. 1887-1895, May 2011.

[12] T. Kerekes, R. Teodorescu, P. Rodriguez, G. Vazquez, and E. Aldabas, "A new high-efficiency single-phase transformerless PV inverter topology,” IEEE Trans. Ind. Electron., vol. 58, no. 1, pp. 184-191, Jan. 2011.

[13] Y., GU, W. Li, Member, Yi Zhao, Bo Yang, C Li, and X. He "Transformerless Inverter with Virtual DC Bus Concept for Cost- Effective Grid-Connected PV Power Systems” IEEE Trans. On power Electronics VOL. 28, NO. 2, Pp.793-805, feb.2012.

[14] T. K. S. Freddy, N. A. Rahim, W. P. Hew, H. S. Che, "Comparison and Analysis of Single- Phase Transformerless Grid- Connected PV Inverters," IEEE Trans. Power Electron. vol. 29, no. 10, pp. 5358-5369, Oct. 2014.

[15] F. T. K. Suan, N. A. Rahim, and H. W. Ping, "Modeling, analysis and control of various types of transformerless grid connected PV inverters,"in Proc. IEEE Clean Energy Technol., June 2011, pp. 51-56.

[16] F. T. K. Suan, N. A. Rahim, and H. W. Ping, "Three phase transformerless grid-connected photovoltaic inverter to reduce leakage currents," in Proc IEEE Clean Energy Technol., Nov. 2013, pp. 51-56.

[17] T. K. S. Freddy, N. A. Rahim, W. P. Hew, H. S. Che, "Modulation Techniques to Reduce Leakage Current in Three- Phase Transformerless H7 Photovoltaic Inverter," IEEE Trans. Ind. Electron. vol. 62, no. 1, pp. 322-331, Jan. 2015.

\section{AURTHORS}

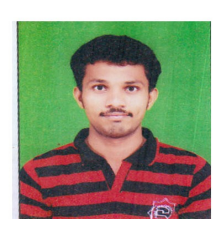

Ahmad Syed received the B.Tech. Degree in Electrical and Electronics Engineering from JNTU Hyderabad in 2008.He is currently working towards the Ph.D. degree in Electrical and Electronics Engineering from Jawaharlal Nehru technological university (JNTU) Hyderabad. His research interests include transformerless PV inverters, power electronics and renewable energy.

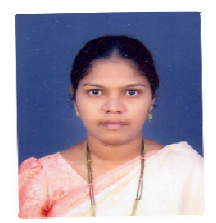

S.Tara Kalyani received the B.Eng. degree in Electrical and Electronics Engineering from Osmania University, Hyderabad in 1995. She received the Ph.D. degree from Jawaharlal Nehru technological university (JNTU) Hyderabad in 2008. she is currently a Professor \& Head in the Dept.of Electrical and Electronics Engineering from JNTU Hyderabad. She has published/presented number of technical research papers in National \& International Journals. Her research interests include Facts Controllers, Power electronics industrial drives and Energy systems. 